BULLETIN (New Series) OF THE

AMERICAN MATHEMATICAL SOCIETY

Volume 38, Number 4, Page 499

S 0273-0979(01)00919-3

Article electronically published on June 12, 2001

\title{
NOTE FROM THE BOOK REVIEWS EDITOR
}

\author{
BHAMA SRINIVASAN
}

In the review of the book "On the local structure of Morita and Rickard equivalences between Brauer blocks" by L. Puig (Bull. Amer. Math. Soc. (N.S.) 38 (2001), 97-100) the following sentence of the reviewer appears: "Although this does not occur explicitly in Puig's book, we mention that the notion which seems to play a particularly important role in block theory is that of splendid equivalence ...." This sentence might be interpreted by a reader as implying that the concept of splendid equivalence is not treated at all in the book. To this end, the author has pointed out to the Book Reviews Editor the following. He mentions the notion of splendid equivalence in the Introduction, 1.12 , p. 5. The author then goes on, in the body of the book, to define a notion which he calls "basic Rickard equivalence", which has a weaker hypothesis than "splendid equivalence" but leads to similar conclusions. He develops this concept in Chapters 13, 17 and 19. In reply the reviewer has pointed out to the Editor that though he agrees that the concept of splendid equivalence is mentioned in the Introduction of the book, it is the concept of basic Rickard equivalence which is defined and successfully studied in the book.

Department of Mathematics, University of Illinois at Chicago, 851 S. Morgan Street, M/C 249, Chicago, IL 60607-7045 